\title{
AN EMPIRICAL NOTE ON WEATHER EFFECTS IN THE AUSTRALIAN STOCK MARKET
}

\begin{abstract}
The behavioural finance literature posits a link between the weather and equity markets via investor moods. This paper examines the impact of weather on the Australian stock market over the period 1958 to 2005 . A regression-based approach is employed where daily market returns on the Australian Securities Exchange's All Ordinaries price index are regressed against eight daily weather observations (precipitation, evaporation, relative humidity, maximum and minimum temperature, hours of bright sunshine, and the speed and direction of the maximum wind gust) at Sydney's Observatory Hill and Airport meteorological stations. Consistent with studies elsewhere including the Australian market, the results indicate that the weather has absolutely no influence on market returns. Some directions for future research that may help address some of the deficiencies found in this intriguing body of work are provided.
\end{abstract}

JEL CODE: C32; G12; G14

KEY WORDS: Weather effects; Market efficiency; Investor moods

\section{INTRODUCTION}

A well-established and diverse literature, primarily in the field of psychology, has investigated the premise that “...weather variables affect an individual's emotional state or mood, which creates a predisposition to engage in particular behaviours" (Howarth and Hoffman, 1984, p. 15). An almost equally well-known theoretical extension has examined the importance of moods in economic decision-making (see, e.g., Elster, 1998; Loewenstein, 2000; Romer, 2000; Loewenstein et al., 2001; Hanock, 2002).

One strand of this work suggests that the moods of investors may affect equity prices if investor's subjective preferences (including the level of risk aversion and their judgement of the appropriate discount rate) fluctuate over time, if the effects of these fluctuations are widely and uniformly experienced, and if investors do not realise their decisions are influenced by fluctuations in their moods (Mehra and Sah, 2002). Lucey and Dowling (2005) provide a useful survey of the role of moods in investor decision-making. Critically, this complements very recent empirical work that has sought to investigate whether the positive (negative) moods induced by good (bad) weather cause a mood misattribution that results in marginal investors pricing stocks more optimistically (pessimistically) (see, e.g., Saunders, 1993; Keef and Roush, 2003; Hirshshleifer and Shumway, 2003; Pardo and Valor, 2003; 
Garrett et al., 2003; Loughran and Schultz, 2004; Goetzmann and Zhu, 2005; Cao and Wei, 2005).

The purpose of this note is to add to this intriguing body of work the results of an analysis of weather and its impact on the Australian equity market. Although the Australian market has been partially addressed in studies of international weather effects by Hirshleifer and Shumway (2003), Cao and Wei (2005) and Garrett et al. (2005), a comprehensive analysis remains, as yet, undone. Using daily data over a long time period, and a wide range of weather indicators as proxies for mood factors, this paper confirms that there is no evidence to support the presence of a weather effect in Australian stock returns.

The remainder of the note is organised as follows. Section 2 briefly reviews the literature on weather and its influence on investor decision making. Section 3 explains the empirical methodology and data employed in the study and Section 4 provides a descriptive analysis. The empirical findings are presented and analysed in Section 5. The paper ends with a brief conclusion.

\section{LITERATURE REVIEW}

The seminal paper on the relationship between weather-induced moods and equity returns is Saunders (1993). Using daily returns from the Dow-Jones Industrial Average from 1927 to 1989 and the New York Stock Exchange and American Stock Exchange from 1962 to 1989, Saunders (1993) examined whether any systematic variation in these markets could be associated with local weather patterns (as observed at New York Central Park from 1927 to 1960 and New York LaGuardia Field from 1961 to 1989). Weather was defined in the form of cloud cover. The results indicated that when cloud cover was 100 percent, returns were below average, but when cloud cover was below 20 percent, returns were above average.

Following these remarkable and rather well-publicised findings (see, e.g., Stecklow, 1993; Koretz, 1994) a number of other studies also examined the relationship between weather and stock returns. Trombley (1997, p. 18) reexamined the Dow-Jones Industrial Average over the period 1927 to 1989 and concluded that “...the relationship between security returns and Wall Street weather is neither as clear nor as strong as Saunders (1993) suggests. There is no difference between returns on clear sunny days and on cloudy or rainy days”. Krämer and Runde (1997) also investigated cloud cover, though in the context of the German stock index (DAX) and with three additional weather indicators observed at Frankfurt - humidity, 
atmospheric pressure and rainfall. Krämer and Runde (1997) also concluded that no systematic relationship seemed to exist.

Similar results were quickly confirmed in Turkey (Tufan and Hamarat, 2004), New Zealand (Keef and Roush, 2003) and Spain (Pardo and Valor, 2003). However, Keef and Roush (2003) did find some evidence of a negative temperature and wind effect (as measured at Wellington) on New Zealand stock returns, afterwards a positive sunshine and negative wind effect (Keef and Roush, 2005), and later still a latitude-dependent cloud cover effect (Keef and Roush, 2007b). Dowling and Lucey (2005) also examined a range of weather indicators (as measured at Dublin Airport) for the Irish Stock Exchange, including cloud, precipitation, humidity and the presence of geomagnetic storms, concluding that rain was a minor but significant market influence.

Internationally, Hirshleifer and Shumway (2003) considered the relationship between cloud cover and equity returns in 26 markets. As with Saunders (1993), a negative relationship between cloud cover and returns was found, but only in three cases of cloud cover (Milan, Rio de Janeiro and Vienna) and two cases of precipitation (Brussels and New York) were they significant. Cao and Wei (2005) reexamined the international weather effect, though with temperature, concluding a negative correlation between temperature and returns. However, the effect was not ubiquitous.

Finally, Kamstra et al. (2003) and later Garrett et al. (2005) investigated the role of seasonal affective disorder (clinical depression associated with shorter winter days) in influencing market returns. These studies built on earlier work by Kamstra et al. (2000) of a daylight saving effect (for rebuttals, see Pinegar, 2002; Worthington, 2003). Kamstra et al. (2003, p. 14) concluded that the results “...were consistent with a [seasonal affective disorder]-induced pattern in returns as depressed and risk-averse investors shun risky assets in the fall and resume their risky holdings in the winter, leading to returns in the fall which are lower than average and returns following the longest night of the year which are higher than average”. Garrett et al. (2005) later found that the seasonal affective disorder effect arose due to the heightened risk aversion that came with seasonal depression, as reflected by a changing risk premium.

\section{EMPIRICAL METHODOLOGY}

The approach used to test for weather effects in Australian stock returns is regression-based 
where market returns are regressed against a set of weather observations. The following model is specified:

$$
R_{t}=\beta_{0}+\sum_{i=1}^{N} \beta_{i} W_{i t}+\varepsilon_{t}
$$

where $\mathrm{R}_{t}$ represents the market return on day $t, W_{i t}$ are observations for the $i$ th weather-related variable on day $t$ (where $i=1,2 \ldots \mathrm{N}$ ), $\beta$ are parameters to be estimated and $\varepsilon$ is the error term.

The market data employed are closing prices from the Australian Securities Exchange (ASX) and a predecessor (Sydney stock exchange) from Monday 6 January 1958 to Friday 30 December 2005. This sample encompasses 12,067 trading days and represents the most complete set of daily data available. The capitalization-weighted All Ordinaries Price Index is used. The index covers about 92 percent of domestic companies by market value. To be included in the index, stocks must have an aggregate market value of at least 0.02 percent of all domestic equities, and maintain an average turnover in excess of 0.5 percent of quoted shares each month. The long-term index includes base recalculations by Global Financial Data (2006). A series of market returns are then calculated as $R_{t}=100 \ln \left(P_{t} / P_{t-1}\right)$ where $P_{t}$ is the index at the end of day $t$.

The weather data used in the study are sourced from the NSW Climate and Consultancy Section of the Australian Bureau of Meteorology (2006). The weather stations selected for this analysis (latitude and longitude in brackets) are \#066062 Sydney Observatory Hill (33.8607, 151.2050) and \#066037 Sydney Airport (-33.9411, 151.1725). The former has operated continuously since July 1858 and the latter since September 1929. Sydney is selected over other possible market locations (Melbourne, Brisbane, Adelaide and Perth) because the early market data is largely compiled from old Sydney stock exchange indices. Moreover, Sydney is well accepted as Australia's financial capital, with existing international work on the weather effect, including Hirshleifer and Shumway (2003), Cao and Wei (2005) and Garrett et al. (2005), also specifying weather conditions at Sydney.

Most of the observations in the study are taken from Observatory Hill as this is the closest station to the CBD and offers the most complete record. Any missing data are extracted from the Airport (about ten kilometres south). However, other than some missing data owing to faulty equipment or missed observations, the only systematic variation is that sunshine and evaporation observations originally taken at Observatory Hill have been more recently gathered at the Airport. 
Eight weather elements are extracted on a daily basis. These are: precipitation $(\mathrm{mm})$, evaporation (mm), relative humidity (\%), maximum temperature $(\mathrm{C})$, minimum temperature $\left({ }^{\circ} \mathrm{C}\right)$, hours of bright sunshine $(\mathrm{n})$, speed of maximum wind gust $(\mathrm{km} / \mathrm{h})$ and direction of maximum wind gust $\left({ }^{\circ}\right)$. While these represent, for the most part, a substantially broader representation of weather than existing work, the specification of the individual elements draws heavily on the extant literature. For example, Krämer and Runde (1997) and Hirshleifer and Shumway (2003) specify total sky cover (i.e. cloudiness), Cao and Wei (2005) include daily temperature, Keef and Roush (2003) measure sunshine, humidity, rainfall, high and low temperature and wind gust speed and direction, and Dowling and Lucey (2005) specify cloudiness, rain and humidity. By way of comparison, in similar studies of weather effects that include Australia (read Sydney), Hirshleifer and Shumway (2003) specified morning sunshine after controlling for precipitation, Cao and Wei (2005) included temperature only, and Garrett et al. (2005) specified the length of the day based on latitude and season.

Importantly, it is difficult to find exactly what cognitive and/or affective constructs weather observations proxy in the finance literature. Generally, higher levels of precipitation, humidity and wind power are thought to have negative affect while hours of sunshine and maximum temperature may have positive affect (though these vary across the range of values). For instance in the psychology literature, negative affect is linked with positive survey response like alert, active, attentive, enthusiastic and excited; negative affect is linked with nervous, jittery, irritable, upset and distressed; and tiredness with sleepy, tired, sluggish and drowsy (Denissen et al. 2008). We return to this problem in the conclusion.

\section{DESCRIPTIVE ANALYSIS}

Table 1 includes descriptive statistics for daily returns, precipitation, evaporation, relative humidity, maximum and minimum temperatures, hours of bright sunshine, and the speed and direction of the maximum wind gust. As shown (to two-decimal places only), the mean daily return is about 0.03 percent. In terms of weather, a typical Sydney day comprises precipitation of $3.43 \mathrm{~mm}$, evaporation of $4.48 \mathrm{~mm}$, humidity of 63.02 percent, a maximum temperature of 22.18 degrees and a minimum of 14.20 degrees, with 6.90 hours of bright sunshine and a maximum wind gust of $44.91 \mathrm{~km} / \mathrm{h}$ blowing from the south. However, all of the market and weather variables are highly volatile (as measured by the coefficient of variation). Market returns are substantially more volatile (28.52) than the weather variables, of which 
precipitation (3.29) and hours of bright sunshine (0.55) are more variable, while maximum temperatures (0.20) and humidity (0.22) are least variable.

\section{$<$ TABLE 1 HERE $>$}

Commonsense suggests that the weather variables should be highly correlated. This is supported by correlation analysis (not shown). Because of the potential for multicollinearity, variance inflation factors are also calculated (not shown) where each weather variable is regressed on the other weather variables, with the variance inflation factor calculated as one divided by one minus the $\mathrm{R}^{2}$. As a rule, a variance inflation factor greater than ten is an indicator of potentially harmful multicollinearity. As the largest variance inflation factor among the eight weather variables is only 4.66, the potential problems arising from multicollinearity are not great. In addition, the non-normality of the returns suggested by distributional testing (not shown) is generally not regarded as too severe a problem with very large samples.

\section{EMPIRICAL RESULTS}

The estimated coefficients and standard errors of the parameters detailed in (1) are presented in Table 2. Three different standard errors and $p$-values are calculated and presented for the regression model. These are standard errors and $p$-values obtained by: (i) ordinary least squares, (ii) those employing corrections for heteroskedasticity of unknown form (White), and (iii) those incorporating corrections for heteroskedasticity and autocorrelation of unknown form (Newey-West).

\section{$<$ TABLE 2 HERE $>$}

As shown in Table 1, none of the least squares coefficients are significant at any conventional level. Breusch-Godfrey Lagrange multiplier and White's heteroskedasticity tests are used to test for higher-order serial correlation and heteroskedasticity in the least squares residuals, respectively. To start with, the null hypothesis of no serial correlation is rejected (statistic $=46.64, p$-value $=0.01$ ) and we conclude the presence of higher-order serial correlation in the residuals. Then the null hypothesis of no heteroskedasticity in the least squares residuals fails to be rejected (statistic $=0.82, p$-value $=0.99$ ). A Lagrange multiplier test for autoregressive conditional heteroskedasticity (ARCH) in the residuals is also 
conducted. The null hypothesis of no ARCH is rejected (statistic $=23.35, p$-value $=0.01)$. As a very general test for specification error in the functional form, Ramsey's RESET test is also conducted. This fails to reject the null hypothesis that the estimators are unbiased and consistent (statistic $=0.86, p$-value $=0.55)$.

After corrections are made for heteroskedasticity (White) and heteroskedasticity and autocorrelation (Newey-West) of an unknown form all of the parameters in Table 2 are again found to be insignificant, even at the .10 level [for the Newey-West estimation the truncation lag of 11 (the parameter representing the number of autocorrelations used in evaluating the dynamics of the OLS residuals) is determined by the automatic routine in EViews 5.1]. An alternative would be to model the ARCH effects directly as in Chang's et al. (2006) study of weather anomalies in Taiwan using the Glosten et al. (1993) GJR-GARCH model, especially as Brailsford and Faff (1993) have found this works particularly well with Australian data. A redundant variables test is conducted for the eight weather factors (precipitation, evaporation, humidity, maximum temperature, minimum temperature, sunshine, maximum wind gust and direction of maximum wind gust) with the null hypothesis that all the coefficients are jointly zero failing to be rejected (statistic $=1.19, p$-value $=0.29$ ). Clearly, weather effects offer no significant explanatory power for market returns in Australia.

While these results contravene some early findings on a weather effect in stock markets, they are very consistent with the small number of international studies that have included Australia. Hirshleifer and Shumway (2003) first incorporated Australia among 26 markets in an analysis of the relationship between weather (as defined by cloud cover and precipitation) and market returns. While a negative relationship between cloud cover and returns was found, only in three cases of cloud cover and two cases of precipitation were the estimated coefficients significant. Neither was in Australia. Later, Cao and Wei (2005) reexamined the international weather effect with temperature. Once again, no evidence of a weather effect was found in the majority of cases, including Australia. The findings do lie counter, however, to Garrett's et al. (2005) findings that a seasonal affective disorder effect existed in six international markets, including Australia. 1. They also contrast with Keef and Roush (2007a) who found evidence of a significant temperature effect in Australia, but no evidence to support wind or cloud cover effects. However, there are a number of methodological differences that make direct comparison with the latter difficult. For instance, Keef and Roush 
(2007a) sampled the period 1992-2003, modelled abnormal returns and bootstrapped standard errors.

\section{CONCLUDING REMARKS}

A small but increasing volume of work has been concerned with the relationship between weather-induced moods and equity market behaviour. This follows evidence that some weather variables affect individual moods, and potentially, actual investor behaviour. Building upon limited evidence concerning the Australian market, this study explores the link between a range of weather indicators and market returns over the last 47 years. The results indicate that there is no statistically significant relationship between the weather and market returns in Australia. This confirms evidence by Hirshleifer and Shumway (2003) and Cao and Wei (2005) concerning the Australian market individually, though both came out in favour of a weather effect on the balance of international evidence.

The fundamental difficulty with this literature is that it effectively ignores the underlying psychological link between weather and moods as a starting point for the connection between mood and investor decisions. In this psychology literature, mood is often conceptualised within a circumplex structure of affect where the dimensions of valence (unpleasantness vs. pleasantness) and arousal (low vs. high) are distinguished, though recent work has also included tiredness (Denissen et al. 2008). Unfortunately, there are very few psychological studies on the association between weather and mood, and the evidence is generally weak. For example, Keller et al. (2005) and Watson (2000) found no consistent main effects of weather on mood while Denissen et al. (2008) revealed that although there were main effects of temperature, wind power and sunlight on negative affect, and sunlight had a main effect on tiredness, the average effect of weather on mood (in terms of explained variance) was only small. It is plainly difficult to reconcile this weak weather-mood link found in the meticulous psychology literature with the often strong (yet indirect) weather-market connection found in the finance literature, but not in this paper.

Clearly, what is required is for the finance literature to put aside further testing of the indirect relationship between weather and markets, with its inherent complications with model misspecification, and instead address the direct connections between mood and investor decision-making. One way forward would be to follow the work of Loughran and Schultz (2004) and Goetzmann and Zhu (2005) by directly modelling investor decision making 
through simulated laboratory experiments. Interdisciplinary work could then be used to tests the link between mood and weather in the manner of the established psychology literature.

\section{REFERENCES}

Brailsford, T. R. Faff, 1993. Modelling Australian stock market volatility, Australian Journal of Management 18: 109-132.

Bureau of Meteorology, 2006. [Online] URL: http://www.bom.gov.au/, Accessed February 2006.

Cao, M., J. Wei, 2005. Stock market returns: A note on temperature anomaly, Journal of Banking and Finance 29: $1559-1573$.

Chang, T., C. Nieh, , M. Yang, and T. Yang, 2006. Are stock market returns related to weather effects? Empirical evidence from Taiwan, Physica A 364: 343-354.

Dowling, M., B. Lucey, 2005. Weather, biorhythms, beliefs and stock returns - Some preliminary Irish evidence, International Review of Financial Analysis 14: 337-355.

Elster, J., 1998. Emotions and economic theory, Journal of Economic Literature 36: 47-74.

Denissen, J.J.A., L. Butalid, L. Penke, M.A. van Aken. 2008. The effects of weather on daily mood: A multilevel approach, Emotion 8: 662-667.

Garrett, I., M.J. Kamstra, L.A. Kramer, 2005. Winter blues and time variation in the price of risk, Journal of Empirical Finance 12: 291-316.

Global Financial Data, 2006. [Online] URL: http://www.globfindata.com, Accessed February 2006.

Glosten, L., R. Jagannathan, D. Runkle, 1993. On the relation between the expected value and the volatility of the nominal excess return on stocks, Journal of Finance 48: 1779-1801.

Goetzmann, W.N., and N., Zhu, 2005, Rain or shine: Where is the weather effect? European Financial Management 11: 559-578.

Hanock, Y., 2002. Neither an angel nor an ant: Emotion as an aid to bounded rationality, Journal of Economic Psychology 23: 1-25.

Hirshleifer, D., T. Shumway, 2003. Good day sunshine: Stock returns and the weather, Journal of Finance 58 : 1009-1032.

Howarth, E., M.S. Hoffman, 1984. A multidimensional approach to the relationship between mood and weather, British Journal of Psychology 75: 15-23.

Kamstra, M. J., L.A. Kramer, M.D. Levi, 2000. Losing sleep at the market: The daylight-savings anomaly. American Economic Review 90: 1005-1011.

Kamstra, M. J., L.A. Kramer, M.D. Levi, 2002. Losing sleep at the market: The daylight saving anomaly: Reply, American Economic Review 92: 1257-1263.

Kamstra, M. J., L.A. Kramer, M.D. Levi, 2003. Winter blues: A sad stock market cycle, American Economic Review 93: 324-343.

Keef, S.P., M.L. Roush, 2003. The weather and stock returns in New Zealand, Quarterly Journal of Business and Economics 41: 61-79.

Keef, S.P., M.L. Roush, 2005. Influence of weather on New Zealand financial securities, Accounting and Finance 45: 415-437.

Keef, S. M. Roush, 2007a. Daily weather effects on the returns of Australian stock indices, Applied Financial Economics 17: 173-184.

Keef, S. M. Roush, 2007b. A meta-analysis of the international evidence of cloud cover on stock returns, Review of Accounting and Finance 6: 324-338.

Keller, M.C., B.L. Frederickson, O. Ybarra, S. Côté, K. Johnson, J. Mickels, A. Conway, T. Wagner, 2005. A warm heart and a clear head, Psychological Science 16: 724-731.

Koretz, G., 1994. Why investors should watch the weather channel, Business Week 14 February, 20. 
Kramer, W., R. Runde, 1997. Stocks and the weather: An exercise in data mining or yet another capital market anomaly? Empirical Economics 22: 637-641.

Loewenstein, G., 2000. Emotions in economic theory and economic behaviour, American Economic Review 65: 426-432.

Loewenstein, G.F., Elke, U.W., Christopher, K.H., Welch, N., 2001. Risk as feelings, Psychological Bulletin 127: 267-286.

Loughran, T., P. Schultz, 2004. Weather, stock returns, and the impact of localized trading behaviour, Journal of Financial and Quantitative Analysis 39: 343-640.

Lucey, B., M. Dowling, 2005. The role of feelings in investor decision-making, Journal of Economic Surveys 19: 211-237.

Mehra, R., R. Sah, 2002. Mood fluctuations, projection bias and volatility of equity prices, Journal of Economic Dynamics and Control 26: 869-887.

Pardo, A., E. Valor, 2003. Spanish stock returns: Rational or weather-influenced? European Financial Management 9: 117-126.

Pinegar, J. M., 2002. Losing sleep at the market: Comment, American Economic Review 92: 1251-1256.

Romer, P.M., 2000. Thinking and feeling, American Economic Review 83: 1337-1345.

Saunders, E. M., 1993. Stock prices and Wall Street weather, American Economic Review 83: 1337-1345.

Stecklow, S., 1993. For stock market advice, just call the meteorologist for Manhattan, Wall Street Journal 28 December, 1.

Trombley, M.A., 1997. Stock prices and Wall Street weather: Additional evidence, Quarterly Journal of Business and Economics 36: 11-21.

Tufan, E., B. Hamarat, 2004. Do cloudy days affect stock exchange returns: Evidence from Istanbul stock exchange, Journal of Naval Science and Engineering 2: 117-126.

Worthington, A.C., 2003. Losing sleep at the market: An empirical note on the daylight saving anomaly in Australia, Economic Papers 22: 83-93. 
Table 1. Descriptive analysis of daily returns and weather observations

\begin{tabular}{lrrrrrrrrr}
\hline & \multicolumn{1}{c}{$\begin{array}{c}\text { Returns } \\
(\%)\end{array}$} & $\begin{array}{c}\text { Precipitation Evaporation } \\
(\mathrm{mm})\end{array}$ & $\begin{array}{c}\text { Relative } \\
\text { humidity } \\
(\%)\end{array}$ & $\begin{array}{c}\text { Maximum } \\
\text { temperature } \\
\left({ }^{\circ} \mathrm{C}\right)\end{array}$ & $\begin{array}{c}\text { Minimum } \\
\text { temperature } \\
\left({ }^{\circ} \mathrm{C}\right)\end{array}$ & $\begin{array}{c}\text { Hours of } \\
\text { bright } \\
\text { sunshine } \\
(\mathrm{n})\end{array}$ & $\begin{array}{c}\text { Speed of } \\
\text { maximum } \\
\text { wind gust } \\
(\mathrm{km} / \mathrm{h})\end{array}$ & $\begin{array}{c}\text { Direction of } \\
\text { maximum } \\
\text { wind gust } \\
\left({ }^{\circ}\right)\end{array}$ \\
\hline Mean & 0.0295 & 3.4381 & 4.4839 & 63.0171 & 22.1838 & 14.2044 & 6.8952 & 44.9069 & 167.5908 \\
Median & 0.0431 & 0.0000 & 4.4839 & 64.0000 & 22.0000 & 14.4000 & 7.9000 & 42.5000 & 180.0000 \\
Maximum & 7.0162 & 327.6000 & 17.8000 & 99.0000 & 42.4000 & 26.6000 & 13.7000 & 135.4000 & 360.0000 \\
Minimum & -28.7611 & 0.0000 & 0.0000 & 12.0000 & 9.3000 & 2.7000 & 0.0000 & 5.4000 & 15.0000 \\
Std. Dev. & 0.8413 & 11.3004 & 2.4177 & 14.1257 & 4.4172 & 4.3908 & 3.8171 & 15.8693 & 89.9621 \\
CV & 28.5186 & 3.2868 & 0.5391 & 0.2241 & 0.1991 & 0.3091 & 0.5535 & 0.3533 & 0.5367 \\
\hline
\end{tabular}

Notes: Sample period comprises 12,067 trading days from Monday 6 January 1958 to Friday 30 December 2005. All weather observations are compiled from Sydney Observatory Hill \#66062 with missing data and recent evaporation and sunshine observations from Sydney Airport \#66037. Wind directions are compass directions in degrees, i.e. 360 (N), 45 (NE), 90 (E), 135 (SE), 180 (S), 225 (SW), 270 (W), 315 (NW). CV - coefficient of variation.

Table 2. Estimated coefficients and standard errors

\begin{tabular}{lccccccc}
\hline & & \multicolumn{2}{c}{ Least squares } & \multicolumn{2}{c}{ White } & \multicolumn{2}{c}{ Newey-West } \\
\multicolumn{1}{c}{ Independent } & Coefficient & Std. error & $p$-value & Std. error & $p$-value & Std. error & $p$-value \\
\hline Constant & 0.0968 & 0.0903 & 0.28 & 0.0867 & 0.26 & 0.0902 & 0.28 \\
Precipitation & 0.0002 & 0.0007 & 0.79 & 0.0007 & 0.77 & 0.0006 & 0.76 \\
Evaporation & 0.0022 & 0.0039 & 0.57 & 0.0040 & 0.58 & 0.0042 & 0.60 \\
Relative humidity & -0.0011 & 0.0008 & 0.19 & 0.0008 & 0.17 & 0.0008 & 0.17 \\
Maximum temperature & 0.0016 & 0.0035 & 0.63 & 0.0036 & 0.64 & 0.0038 & 0.66 \\
Minimum temperature & -0.0002 & 0.0038 & 0.95 & 0.0039 & 0.95 & 0.0040 & 0.95 \\
Hours of bright sunshine & 0.0008 & 0.0029 & 0.78 & 0.0029 & 0.78 & 0.0029 & 0.78 \\
Speed of maximum wind gust & -0.0005 & 0.0005 & 0.33 & 0.0005 & 0.31 & 0.0006 & 0.34 \\
Direction of maximum wind gust & -0.0002 & 0.0001 & 0.14 & 0.0001 & 0.11 & 0.0001 & 0.13 \\
\hline
\end{tabular}

Notes: Dependent variable is daily returns. Least squares - standard errors and $p$-values from ordinary least squares, White standard errors and $p$-values employing corrections for heteroskedasticity of unknown form, Newey-West - standard errors and $p$ values employing corrections for heteroskedasticity and autocorrelation of unknown form. 